\title{
Perception and Use of Complementary and Alternative Medicine (CAM) among undergraduate students in a Nigerian University
}

\author{
Ufuoma Shalom Ahwinahwi*, Kingsley Chukwudi \\ Clinical pharmacy and Pharmacy Administration, Delta state university; Abraka-Nigeria., Federal University Health Center, Lokoja, Nigeria.
}

\begin{tabular}{|c|c|}
\hline ARTICLE INFO & ABSTRACT \\
\hline Article history: & Objectives: This study was designed to evaluate the Perception and Use of Complementary and Alternative \\
\hline Received on: $28 / 01 / 2016$ & Medicines (CAM) among the undergraduate Students of Delta State University (DELSU), Abraka.-Nigeria. \\
\hline Revised on: 10/03/2016 & Methods: Self- administered questionnaires were distributed randomly to the participants. \\
\hline Accepted on: 07/04/2016 & Result: Out of 450 students that voluntarily participated in the study, $368(81.78 \%)$ had used or were currently \\
\hline Available online: $28 / 06 / 2016$ & using at least one of the various CAM modalities; Family members $(282,37.15 \%)$ appeared to be the most \\
\hline \multirow{5}{*}{$\begin{array}{l}\text { Key words: } \\
\text { Undergraduate Students, } \\
\text { Perception, Use, } \\
\text { Complementary and } \\
\text { alternative medicine. }\end{array}$} & $\begin{array}{l}\text { common source of information and knowledge about CAM while Herbal medicine }(250,37.71 \%) \text { was the most } \\
\text { commonly used and perceived to be the most effective CAM method, and the most popular ailment effectively }\end{array}$ \\
\hline & treated with CAM was Malaria $(142,34.22 \%)$. Pharmacists $(98,45.80 \%)$ played a major role in influencing \\
\hline & their perceptions towards CAM use and the major reason for CAM use was that CAM is Cheaper $(159,27.09 \%)$ \\
\hline & $\begin{array}{l}\text { than Conventional medicine, however, lack of scientific evidence to support CAM practices }(340,31.66 \%) \text { was } \\
\text { obtained as the most prevailing barrier to CAM use. }\end{array}$ \\
\hline & $\begin{array}{l}\text { Conclusion: Majority of undergraduate Students of DELSU used CAM and possessed positive perceptions of } \\
\text { Complementary and Alternative medicine. Concerted efforts should therefore be made by members of the } \\
\text { healthcare team to ensure the safety of these modalities. }\end{array}$ \\
\hline
\end{tabular}

\section{INTRODUCTION}

The National Center for Complementary and Alternative Medicine (NCCAM) at the National Institute of Health (NIH) in United States of America defines Complementary and Alternative Medicine (CAM) as a group of diverse medical and health care systems, practices and products that are not generally considered part of conventional medicine (NIH, 2012). Complementary interventions are health care approaches used in conjunction with conventional interventions, whereas Alternative Medicines are used in place of conventional medicines (Barnes and Bloom, 2008).In the past decades, attention and interest in the use of CAM has reawakened globally, although the evolution of conventional medicines has

\footnotetext{
* Corresponding Author

Ufuoma Shalom Ahwinahwi, Clinical pharmacy and Pharmacy

Administration, Delta state university; Abraka-Nigeria

Email:ushaloma@yahoo.com
}

been growing in popularity and getting increased attention and interest (Levine et al., 2003). The global situation as reported in World Health Organization (W.H.O) Traditional Medicine Strategy 2002-2005 showed a CAM use prevalence rate of Belgium (31\%), China (40\%), Colombia (40\%), U.S.A (42\%), Australia (48\%), France (49\%), India (65\%), Canada (70\%) and Chile (71\%)(W.H.O, 2002). A study carried out among Malaysian Pharmacy students revealed that more than half $(57.8 \%)$ of the participants were currently using CAM while $77.6 \%$ had used it previously (Hassan et al., 2011). A study carried out among Indians who reside in Chatsworth, South Africa also revealed a prevalence rate of $38.5 \%$ (Singh et al., 2004). In Nigeria as noted by the World Health Assembly, Traditional Medicine is partially recognized as forming a part of the National Health Delivery System (WHO, 2003). The most familiar forms of CAM practices in Nigeria would be considered in this study and these include; Herbal Medicines, Dietary supplements, massage therapy, Traditional Bone Setting, Aromatherapy, Hydrotherapy, Faith 
Healing and Traditional Birth Attendance. Also in Nigeria, studies carried out on prevalence of CAM use showed that out of 160 patients interviewed on the use of CAM, prevalence rates of $65.0 \%$ and 35\% was recorded among cancer patients (Ezeome and Anarado, 2007) and children with chronic health condition (Oshikoya et al., 2008) respectively. With these prevalence rates of CAM use in Nigeria and beyond, some significant barriers to CAM use have however been identified to include: insufficient scientific evidence to support its use as well as lack of trained professionals (Hassan et al., 2011); lack of appropriate equipment needed to perform CAM therapies and concern for legality of using CAM methods (Hussain et al., 2012). Despite the increase in global interest of CAM modalities, it is pertinent that consideration be given to the following :

* Sources information about the various CAM practices and their health benefits

* Varied number of perceived barriers to CAM use.

* Different perceptions towards CAM use in terms of unwanted side effects, effectiveness in the treatment and prevention of diseases and their health benefits, as against conventional medicine practices.

- People's attitudes towards CAM use.

\section{Research Questions}

The research questions were developed in a bid to evaluate the aforementioned issues as they affect the prevalence of use and perceptions of CAM among people, using undergraduate Students of Delta State University, Abraka, as subjects for the study. The questions are as follows;

- What is the prevalence of CAM use among the people?

- What are the effective means of passing information about CAM to the people?

- What are the prevailing or perceived barriers that hinder CAM acceptability and preference among the people?

- What do people perceive about the use of CAM as against conventional medicine in terms of health benefits and effectiveness in the treatment and prevention of diseases?

\section{Aim of the Study}

This study is aimed at identifying the prevalence of CAM use, people's attitudes towards CAM as well as their perceptions about CAM, including their perceived barriers to CAM use.

\section{Study Objectives}

The study objectives designed to meet the aims include identifying the following;

1. The proportion of people that use / have used CAM.

2. The common means of passing information about CAM by the providers to the people.

3. The perceived barriers militating against CAM use.

\section{Preference of CAM to conventional medicines}

\section{METHODS}

\section{Study Design}

The cross- sectional survey was carried out among the undergraduate students of Delta State University, Abraka Campus from $24^{\text {th }}$ of March 2013 through April 2013. In order to obtain a more general and comprehensive perceptions and use of Complementary and Alternative Medicines (CAM) among the undergraduate students, the study was conducted among students of various departments within the three (3) sites of the Campus.

Self -administered questionnaires were distributed randomly among the students after oral informed consent was obtained. The students were given considerable time to study and understand the questions and anonymously filled in their responses accordingly, after which the completed questionnaires were collected for analysis.

\section{Development of research instrument}

The questionnaire was developed after detailed review of relevant literatures (Barnes and Bloom, 2008; Levine et al., 2003; Ezeome and Anarado, 2007; Hassan et al., 2011; Tiralongo and Marranne, 2008). In addition, some novel questions were developed in accordance with the study objectives.

Section A described the demography of the respondents while Section B carries the list of various types of CAM prior to the main questions of the research study which is in accordance with the objective of the study.

The questionnaire was worded in English Language and was not translated to other languages as English is the official Language and medium of instructions in the University.

\section{Validation of questionnaires}

Pilot study was conducted by distributing the questionnaires randomly to 20 students of different departments, filled and collected. Through identifying the similarities and differences in response rate at each occasion, the validity of the questionnaire was established; no significant difference was found during this phase.

\section{Ethical issues}

Administrative approval was gotten however; no ethical approval was sought prior to the commencement of the study.

\section{Estimation of Sample Size}

The sample size was calculated based on three (3) factors; Response rate (P), Margin of error (D) and Confidence level (1-P) using Raosoft ${ }^{\circledR}$ sample size calculator.

Based on the calculation with response rate $50 \%$ and margin of error 5\%, the total sample size required for the study was 381 students. However, at the end of the data collection phase, 450 students participated in the study which was more than the calculated sample size to make up for any inadequate responses. 


\section{Sampling}

Simple Random Sampling Method was used for the data collection. During the data collection phase, the questionnaires were distributed randomly to each student within the three (3) sites of the Campus. The participants were given considerable time to study the questions and responded accordingly.

\section{Statistical Analysis}

Descriptive data analysis was carried out for frequencies and percentages and results were presented in tables and figures.

\section{RESULTS}

\section{Social Demographics}

A total of four hundred and fifty students participated in the study. Students between the age range of 21-25 years dominated the study population $(269,59.78 \%)$, followed by those within 16-20 years $(125,27.78 \%)$, 26-30 years $(55,12.22 \%)$ while only one participant $(0.22 \%)$ fell within the age range of 30 years and above. The participants were more of female (245, $54.44 \%)$ than male $(205,45.56 \%)$. Majority of the participants were single $(438,97.33 \%)$, while only $12(2.67 \%)$ were married.

Table I shows the distribution of Social Demographic Characteristics of the study sample population;

Table 1: Demographic Characteristics of the Study population .

\begin{tabular}{lcc}
\hline Characteristics & Frequency & Percentage \\
\hline Age (years) & & \\
\hline$(16-20)$ & 125 & $27.78 \%$ \\
$(21-25)$ & 269 & $59.78 \%$ \\
$(26-30)$ & 55 & $12.2 \%$ \\
$(31$ and above) & 1 & $0.22 \%$ \\
\hline Sex & & \\
\hline Male & 205 & $45.56 \%$ \\
Female & 245 & $54.44 \%$ \\
\hline Marital status & & \\
\hline Single & 438 & $97.33 \%$ \\
Married & 12 & $2.67 \%$ \\
\hline Levels of study & & $7.78 \%$ \\
\hline 100 & 35 & $27.11 \%$ \\
200 & 122 & $31.56 \%$ \\
300 & 142 & $25.33 \%$ \\
400 & 114 & $8.22 \%$ \\
500 & 37 & $\mathbf{1 0 0 \%}$ \\
\hline Total & $\mathbf{4 5 0}$ & \\
\hline
\end{tabular}

\section{Sources of information about CAM}

Interestingly, the most popular source of information about CAM stated by majority of the participants was from Family Members (282, 37.15\%), followed by Radio Adverts (175, $23.06 \%)$. Also a good proportion of the participants $(116,15.28 \%)$ stated that they were taught about CAM in School, while 104 $(13.70 \%)$ and $82(10.80 \%)$ participants got to know about CAM from Television shows and publications such as Newspapers and Books respectively.

\section{Types of CAM used and ailments for which they were used}

Among the various types of CAM used, Herbal Medicine $(250,37.71 \%)$ appeared to be the most commonly used type of
CAM practice followed by Faith healing $(131,19.76 \%)$ and Dietary supplements $(108,16.29 \%)$. Some of the participants reported to have used massage $(82,12.37 \%)$ and Traditional Bone Setting $(52,7.84 \%)$ on several occasions. Others are as shown in table II.

Table 2: Types of CAM used.

\begin{tabular}{lcc}
\hline Types of CAM used & Number of Responses & Percentage \\
\hline Herbal Medicine & 250 & $37.71 \%$ \\
Faith Healing & 131 & $19.76 \%$ \\
Dietary Supplements & 108 & $16.29 \%$ \\
Massage & 82 & $12.37 \%$ \\
Traditional Bone Setting & 52 & $7.84 \%$ \\
Hydrotherapy & 23 & $3.47 \%$ \\
Aromatherapy & 14 & $2.11 \%$ \\
Traditional Birth Attendance & 3 & $0.45 \%$ \\
\hline TOTAL & $\mathbf{6 6 3}$ & $\mathbf{1 0 0 \%}$ \\
\hline
\end{tabular}

Among the ailments/conditions for which CAM was used, Malaria appeared to be the most prevailing with a percentage of $34.22 \%$ (142 students). Others included; stomach pain (37, $8.93 \%)$, Fracture $(34,8.19 \%)$, Body pain (30, 7.23\%), Typhoid fever $(28,6.75 \%)$, "Body maintenance"/ immunity $(15,3.61 \%)$, Skin infections $(14,3.37 \%)$, Headache $(13,3.13 \%)$, Arthritis (9, $2.17 \%)$, spiritual attacks $(9,2.17 \%)$, Dislocation $(9,2.17 \%)$, Ulcer $(6,1.45 \%)$, Waist pain $(6,1.45 \%)$ and Diarrhea $(6,1.45 \%)$, weight reduction $(5,1.21 \%)$ amongst others $(42,12.53 \%)$.

\section{Reasons for CAM use}

Most of the CAM users agreed that the major reason for their use of CAM was because it is cheaper $(159,27.09 \%)$ than conventional medicines, followed by the reason that CAM is more effective $(150,25.55 \%)$, more accessible $(146,24.87 \%)$ and possess less side effects $(132,22.49 \%)$ than conventional medicines.

\section{Perceived barriers to the use of CAM}

Lack of scientific evidence to support CAM practices (340, 31.66\%) was indicated to be the most perceived barrier militating against CAM use, followed in order by; lack of appropriate dose $(326,30.35 \%)$, unhygienic methods of preparation of CAM products $(256,23.84 \%)$, Religious barriers $(95,8.85 \%)$, others are as shown in figure 1

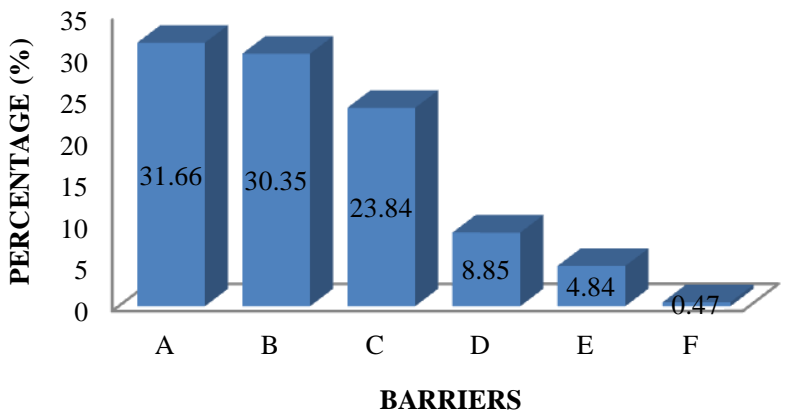

Fig. 1: Percentage Distribution of Perceived Barriers to CAM use. $\mathrm{A}=$ Lack of scientific evidence., $\mathrm{B}=$ lack of appropriate dose., $\mathrm{C}=$ unhygienic methods of preparation., $\mathrm{D}=$ religious barriers., $\mathrm{E}=$ incompatibility with cultures., $\mathrm{F}=$ others $($ cost $)$ 


\section{Prevalence of CAM use}

Among the 450 students that participated in the study, $368(81.78 \%)$ have use one or more of the various forms of CAM at one occasion or the other, while only $82(18.22 \%)$ have never used any of the listed and other forms of CAM practices. Among the students that have used CAM, majority of them $(264,71.74 \%)$ reported using CAM alone, while only a few $(104,28.26 \%)$ said they used CAM together with orthodox medicines. At the time the study was carried out, less than average $(148,40.22 \%)$ were using CAM, while more than average $(220,59.78 \%)$ had used it previously. Only few $(25,9.47 \%)$ of those who used CAM alone reported that there were some fetish practices and incantations associated with CAM, $234(88.64 \%)$ said there was none such 5 $(1.89 \%)$ did not respond to this question.

\section{Perceptions towards CAM use}

Despite the increased drive towards the use of CAM among the participants, over $50 \%$ of the study participant (252, $56 \%$ ) still do not, while less than average $(198,44 \%)$ prefer CAM to orthodox medicines. Their major reason for preference of CAM to orthodox medicines was that CAM is more effective than orthodox medicines $(64,32.32 \%)$. Other reasons were stated as shown in Table III.

Table 3: Reasons for CAM preference.

\begin{tabular}{lcc}
\hline Reasons for CAM preference & Frequency & Percentage \\
\hline More effective & 64 & $32.32 \%$ \\
Reduced side effects & 43 & $21.72 \%$ \\
Cheaper & 28 & $14.14 \%$ \\
Works faster & 19 & $9.59 \%$ \\
Natural and safe & 12 & $6.06 \%$ \\
Ease of preparation and admin & 9 & $4.55 \%$ \\
Compatible with religion & 9 & $4.55 \%$ \\
Assessibility and availability & 5 & $2.53 \%$ \\
Reliability & 3 & $1.53 \%$ \\
No reason & 6 & $3.03 \%$ \\
\hline Total & $\mathbf{1 9 8}$ & $\mathbf{1 0 0 \%}$ \\
\hline
\end{tabular}

Lack of scientific evidence/standardization to support CAM practices $(45,17.86 \%)$ was stated as the main reason for non-preference of CAM to orthodox medicines amongst others as shown in Table IV.

Table 4: Reasons for non-preference of CAM.

\begin{tabular}{lcc}
\hline Reasons for non-preference & Frequency & Percentage \\
\hline Lack of scientific evidence & 45 & $17.86 \%$ \\
Low effectiveness & 43 & $17.06 \%$ \\
Lack of hygiene & 33 & $13.10 \%$ \\
Lack of appropriate dose & 28 & $11.11 \%$ \\
Just prefer orthodox med. & 21 & $8.33 \%$ \\
Risk of side effects & 17 & $6.75 \%$ \\
Unreliability & 13 & $5.16 \%$ \\
Difficulty in preparation & 3 & $1.19 \%$ \\
Bitterness & 3 & $1.19 \%$ \\
Lack of specific indication & 2 & $0.79 \%$ \\
Lack of convenience & 2 & $0.79 \%$ \\
Modernization in medicine & 2 & $0.79 \%$ \\
Lack of cam knowledge & 2 & $0.79 \%$ \\
Slow rate of action & 4 & $1.59 \%$ \\
Fetish practices & 1 & $0.40 \%$ \\
No reason & 33 & $13.10 \%$ \\
\hline Total & $\mathbf{2 5 2}$ & $\mathbf{1 0 0 \%}$ \\
\hline
\end{tabular}

The perceived effectiveness of the various forms of CAM as reported by the participants was as follows; Herbal Medicine $(211,37.54 \%)$, Faith healing $(111,19.75 \%)$, Dietary supplements $(85,15.12 \%)$, Massage $(68,12.10 \%)$, others are as shown in figure II.

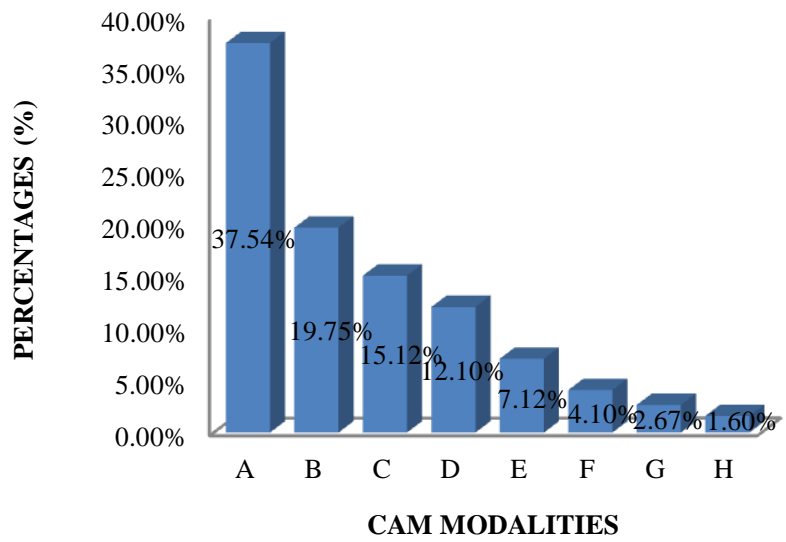

Fig. 2: Perceived effectiveness of CAM modalities.

$\mathrm{A}=$ Herbal medicine., $\mathrm{B}=$ Faith healing., $\mathrm{C}=$ Dietary supplements., $\mathrm{D}=$ Massage $\mathrm{E}=$ Traditional bone setting., $\mathrm{F}=$ Hydrotherapy ., $\mathrm{G}=$ Traditional Birth attendance $\mathrm{H}=$ Aromatherapy

Less than average of the students $(186,41.33 \%)$ were ever influenced by medical practitioners on CAM use with pharmacists having the highest percentage $(80,37.38 \%)$ of influence on CAM use, while 264 (58.67\%) were not

Over $50 \%$ of the students $(253,56.22 \%)$ advocates the use of CAM alone, while 197 (43.78\%) did not. Reasons given for advocating the use of CAM alone were that CAM alone is still effective (103, 40.71\%), avoid adverse drug reactions and side effects $(68,26.88 \%)$, CAM treatment is cheaper when used alone $(19,7.51 \%)$, avoid health complications $(10,3.95 \%)$ among others.

Synergism $(118,76.62 \%)$, increased rate of action (12, $7.79 \%)$, reliability $(7,4.55 \%)$ and reduction of cost of disease treatment $(5,3.25 \%)$ were the reasons given for advocating combined use of CAM with conventional medicines; while 12 (7.79\%) participants did not give any reason.

Table 5: Influence of health Professionals on CAM use.

\begin{tabular}{lcc}
\hline \multicolumn{1}{c}{$\begin{array}{c}\text { Influenced by Health } \\
\text { professionals on CAM use }\end{array}$} & Frequency & Percentage \\
\hline Yes & 186 & $41.33 \%$ \\
No & 264 & $58.67 \%$ \\
Total & $\mathbf{4 5 0}$ & $\mathbf{1 0 0 \%}$ \\
By Pharmacists & 98 & $45.80 \%$ \\
By Doctors & 80 & $37.38 \%$ \\
By Nurses & 36 & $16.82 \%$ \\
\hline Total & $\mathbf{1 8 6}$ & $\mathbf{1 0 0 \%}$ \\
\hline
\end{tabular}

\section{DISCUSSION}

The main source of information about CAM as revealed by the study is from family members which is in contrast to the findings of other previous studies where internet and media (Hassan et al., 2011) and CAM practitioners (Ezeome and Anarado, 2008) were reported to be the main sources of 
information about CAM. This could be as a result of the handing down of traditional medicine practice as a legacy in this locality. However, Newspapers and books were the least effective means of passing information which is likely due to the financial implication of accessing them.

The most commonly used form of CAM practice among the undergraduate Students of DELSU is Herbal Medicine which is next to Faith/ Prayer Healing and Dietary supplements; which is similar to the report in UNTH, Enugu, Nigeria where the most commonly used forms of CAM practice were Herbs (51.90\%), Prayer healing (39.4\%) and forever living products (16.3\%) (Ezeome and Anarado, 2007). Also Singh et al reported that Herbal Medicine and Spiritual healing were two most common forms of CAM practices used amongst the Indians in South Africa while a similar report was given in a Kuwait University, where Herbal Medicine was reported by the students in the departments of Medicine and Pharmacy, to be the most commonly used form of CAM practice (Awad et al., 2012). In contrast, Hassan et al., reported the most common forms of CAM practices in Malaysia were Music and Art therapy, Prayer healing and Meditation therapy (Hassan et al., 2011).

Besides Herbal Medicine, there are other forms of CAM practices used among students of DELSU which included; Massage therapy, Traditional Bone Setting (TBS) and Hydrotherapy. However, Aromatherapy and Traditional Birth Attendance appear to be the least forms of CAM and Traditional Birth attendance was particularly low because most of the students were not married.

Herbal medicine was perceived to be the most effective among all CAM modalities used.

Our study found out that malaria was the most common ailment treated with CAM, in contrast with Diabetes mellitus in South Africa (Singh et al., 2004). This could be due to the high prevalence rate of Malaria in Nigeria and CAM (herbal medicine) efficacy in treating this condition. Malaria is a major public health problem in Nigeria where it accounts for more cases and deaths than any other country in the world and poses risk for $97 \%$ of Nigeria's population (Nigeria Malaria Fact Sheet, 2011) and also the fact that diabetes is associated with increasing age and majority of the student were below 30 years of age.

Among the options given on the reasons for CAM use by the users, Cost (CAM is cheaper) was the commonest reason for CAM use. Hence, people could easily afford CAM treatment without grave effect on their economic life, but with relatively positive/expected result than conventional medicines. Fortunately, this is very important in developing countries like Nigeria where the financially average individuals in urban and rural communities, who cannot afford the high cost of conventional medicines, may have considerable access to good health through CAM use. Also, "less side effects" was stated as a reason for CAM use, a similar report that CAM is a natural and safe form of medical care than conventional medicine which has risks of unwanted side effects was given in South Africa (Singh et al., 2004). The prevalence of CAM use among the undergraduate students was high which is similar to the rates in Canada and Chile (WHO, 2002) as well as prevalence rates reported in Australia (Tiralongo and Marranne, 2008; Wilkinson and Simpson, 2001). However, this was higher than those reported in many other countries; $43 \%$ in United Kingdom (Hon et al., 2004), 38\% in Hong Kong (Freymann et al., 2006), 57.8\% in Malaysia (Syed et al., 2011), 38.5\% in South Africa (Singh et al., 2004), 55.2\% in Kuwait (Awad et al., 2012), $31 \%$ in Belgium, $40 \%$ in China, $40 \%$ in Columbia, $42 \%$ in U.S.A, $49 \%$ in France, $65 \%$ in India (WHO, 2002) and 65\% in Enugu, Nigeria (Ezeome and Anarado, 2007).

Majority of CAM users used CAM alone; while very few used CAM with conventional medicines. This is in contrast with the report in the University of Lagos, where majority of the users would combine CAM with conventional medicine for better efficacy (Agbaje and Babatunde, 2005). Also Singh et al reported that $46.8 \%$ used CAM alone in South Africa, while more (50.7\%) used it together with conventional medicines. The major reason for the combined use of CAM from this study is for synergism just like the report by Agbaje and Babatunde (2005). Although this combined use may have considerable wide safety margin with some CAM modalities (as Dietary Supplements, Massage, Aromatherapy, Hydrotherapy and Faith Healing), it could be extremely dangerous, and in most cases, fatal when Herbal Preparation is involved due to drug interactions.

Majority of the CAM practices were not actually associated with fetish practices as obtained from the large majority of the users reported that no such activity was encountered during preparation and use, although very few reported otherwise.

There is no doubt that despite the global rising trend in CAM use, there still exist a number of challenge, otherwise known as barriers, militating against the general acceptability and implementation of CAM. Similar to other previous studies (Hassan et al., 2011, Yeo et al., 2005, Tiralongo and Murranne, 2008 and Awad et al., 2012), report from this study revealed lack of scientific evidence to support CAM practices to be the most popular barrier against CAM use. Besides, there are other barriers to CAM use and are arranged in other of the extent to which they affects CAM use; lack of appropriate dose, unhygienic methods of preparation, religious barriers, incompatibility with cultural beliefs as well as cost . It could be deduced from this report that cost is the least barrier to CAM use and could be related to the main reason people use/ prefer CAM as reported earlier in this study. Previous studies reported other barriers to include; lack of trained professionals of CAM, lack of Government financial support for CAM, legal issues, lack of appropriate equipment needed to perform CAM therapies (Hassan et al., 2011, Hussain et al., 2012; Tiralongo and Marranne, 2008;Awad et al., 2012). Less than average of the participants preferred CAM to conventional medicine, while majority preferred conventional medicine to CAM. This is in contrast to the report in South Africa where the participants showed low (14.3\%) preference for conventional medicine, and high $(51.9 \%)$ preference for CAM (Singh et al., 2004) but similarly, majority of the patients in the UNTH expressed their opinion that they would not recommend CAM to 
their friends and relatives, while only few would recommend it (Ezeome and Anarado, 2007). Among the reasons given for the preference of CAM from this study, its efficacy was reported to be the most popular reason, followed by its low risk off side effects and cost reduction, while those that did not prefer CAM stated their major reasons to include; lack of scientific evidence to support CAM use, reduced efficacy, as well as unhygienic and crude nature of CAM products among others. These reasons given for CAM preference can be related to the reasons for CAM use reported in this study, while those for non- preference are similar to the barriers to CAM use also reported in this study as well as other previous studies (Hassan et al., 2011;Yeo et al., 2005; Tiralongo and Marranne, 2008;Awad et al., 2012). Therefore, it could be stated that people do not prefer CAM due to the challenging barriers to CAM use. Also similar to this study report, Singh et al. (2004) reported that some of the participants in South Africa preferred CAM because of it is a natural and safe form of medicine, in other words, CAM has reduced risk of side effects. Some of the participants reported being encouraged by healthcare professionals on CAM use. Most of the participants advocated the use of CAM alone and stated their major reasons to include that CAM is still effective when used alone. Those who advocated the combined use of CAM with conventional medicine were of the opinion that the combination would be synergistic and more reliable than whole use, similar to the report in University of Lagos (Agbaje and Babatunde, 2005) and UNTH (Ezeome and Anarado, 2007).

\section{CONCLUSION}

The prevalence of CAM use in this study was high and the students possessed positive perceptions towards CAM, efforts should therefore be made by both the government and other stakeholders in the healthcare system to ensure the safety of these modalities. The pharmacists especially should be poised to give adequate information on the use of these modalities especially as it relates to either negative or positive (synergistic) drug interactions.

\section{REFERENCES}

Agbaje EO, Babatunde EO. A Study of the Attitudes and Practice of Traditional Medicines in Contemporary Nigerian Community. The Cent Afri J Med., 2005; 51(5-6):58-62.

Awad AI, Al-Ajmi S, Waheedi MA. Knowledge, Perceptions and Attitudes towards CAM therapies among Kuwait Medical and Pharmacy Students.Medical principles and Practice, 2012; 21:350-354.

Barnes PM, Bloom B. 2008. Complementary and Alternative Medicine use among adults and children:United States, 2007.National Health Statistics Reports. Number 12:1-23

Ezeome ER, Anarado AN. Use of Complementary and Alternative Medicine by Cancer patients at the University of Nigeria Teaching Hospital, Enugu, Nigeria.BMC Complementary and Alternative Medicine, 2007;7:28
Freymann H, Rennie T, Bates I, Nebel S, Heinrich M. Knowledge and uses of Complementary and Alternative Medicines among Pharmacy British Undergraduate pharmacy students. Pharm World Sci, 2006; 28 (1):13-8.

Hassan SS, Yong CS, Baber MG, Naing CM, Hameed A et al. Understanding, Perceptions and Self use of Complementary and Alternative Medicines among Malaysia Pharmacy Students. BMC Cmplementary and Alternative Medicine, 2011; 11:95

Hussain S, Malik F, Hameed A, Ahmed S, Riaz H, Abbasi N, Malik M. Pakistani Pharmacy Students' Perceptions about Complementary and Alternative Medicine; American Journal of Pharmaceutical Education, 2012; 76(2):21.

Levine SM, Wener-Levine ML, Mayberry RM. Complementary and Alternative Medicine Practices; Training experience and Attitude of a primary care Medical School Faculty. J Am Board FamPract. 2003;16:318-326.

National Center for Complementary and Alternative Medicines (NCCAM) at National Institute of Health (NIH).What is Complementary and Alternative and medicine?. Available at: htpp://www.nccam.nih.gov. (Accessed November 2012).

Nigeria Malaria Fact Sheet (2011 Dec.):Economic Section, United States Embassy in Nigeria. Available at:http://www.nigeria.usembassy.gov, (Accessed November 2012).

NIH Seniorhealth. What is Complementary and Alternative

Medicine? Available

http://www.nihseniorhealth.gov/cam/whatiscam/01.html.(Accessed;

December 2012).

Oshikoya KA, Senbanjo IO, Njokanma OF, Siope A.Use of Complementary and Alternative Medicines for Children with chronic health conditions in Lagos, Nigeria. BMC Complementary and Alternative Medicines,2008; 8:66.

Singh V, Raidoo DM, Harries CS .The Prevalence, Pattern of Usage and Peoples' attitudes towards CAM among Indian Community in Chatsworth, South Africa.BMC Complementary and Alternative Medicine, 2004; 4:3

Tiralongo E, Marranne W.Attitudes and Perceptions of Australian Pharmacy Students towards Complementary and Alternative Medicines- a pilot study. BMC Complementary and Alternative Medicine, 2008; 8:2

Wilkinson JM, Simpson MD.Complementary therapy used by Nursing, Pharmacy and Biomedical Science Students. Nurs Health Sci ,2001; 3 (1):19-27

World Health Organisation (WHO 2002): Traditional Medicine Strategy 2002-2005 Geneva.

World Health Organisation (WHO 2003): World Health Assembly (WHA) Resolutions 56:31. Traditional Medicine: Fifty Six World Assembly, Geneva.

Yeo AS, Yeo JC, Yeo C, Lee CH, Lim LF, Lee TL.Perceptions of Complementary and Alternative Medicines among Medical Students in Singapore - a survey; Acupunct Med, 2005;23:19-26

\section{How to cite this article:}

Ahwinahwi US, Chukwudi K. Perception and Use of Complementary and Alternative Mediciine (CAM) among undergraduate students in a Nigerian University. J App Pharm Sci, 2016; 6 (06): 096-101. 